23 - ORIGINAL ARTICLE CLINICAL RESEARCH

\title{
Correlation between the presence of inguinal hernia and the intensity of lower urinary tract symptoms ${ }^{1}$
}

\author{
Correlação entre a presença de hérnia inguinal e a intensidade dos sintomas do trato urinário \\ inferior
}

\begin{abstract}
Rodolfo Borges dos Reis ${ }^{\mathrm{I}}$, Antonio Antunes Rodrigues Neto ${ }^{\mathrm{II}}$, Leonardo Oliveira Reis ${ }^{\mathrm{III}}$, Roberto Dias Machado ${ }^{\mathrm{IV}}$, Steven Kaplan ${ }^{\mathrm{V}}$
IPhD, Assistant Professor, Division of Urology, Department of Surgery and Anatomy, FMRP-USP, Ribeirao Preto-SP, Brazil. Responsible for intellectual and scientific content of the study, acquisition and interpretation of data, for manuscript preparation and writing, critical revision, designed the protocol, Involved with technical procedures, supervised all phases of the study.

IIPhD, Division of Urology, Department of Surgery and Anatomy, FMRP-USP, Ribeirao Preto-SP, Brazil. Critical revision, helped with technical procedures, collection and processing of study informations.

IIIPhD, Assistant Professor, Division of Urology, Department of Surgery, University of Campinas (UNICAMP), Sao Paulo, Brazil. Critical revision. ${ }^{\text {Iv }}$ MD, Barretos Cancer Hospital, Pio XII Foundation, Barretos-SP, Brazil. Critical revision.

${ }^{v}$ MD, Department of Urology, Weill Cornell Medical College, New York- Presbyterian Hospital, Cornell University, New York, NY, USA, Critical revision, supervised all phases of the study.
\end{abstract}

\begin{abstract}
PURPOSE: To verify the correlation between the presence of IH and the intensity of LUTS related to BPH quantified through the International Prostate Symptom Score (IPSS).

METHODS: We prospectively selected 52 patients over the age of 55years; Patients were divided into 2 groups. Group 1: composed of 32 patients with IH; Group 2 (control group): composed of 20 patients with no clinical evidence of IH. All patients were assessed using the IPSS, uroflowmetry (Qmax), post-void residual urine volume (PVR) and prostate volume (PV).

RESULTS: Groups 1 and 2 presented no difference in PV ( $>>0.05)$ and uroflowmetry (Qmax) ( $>0.05)$. There was a statistical significant difference between the PVR mean values between groups 1 and 2. The presence of IH correlated with a higher IPSS score $(\mathrm{r}=0.38 \mathrm{p}<0.05)$ despite the fact the no difference was detected between the incidence of patients with mild, moderate and severe LUTS in groups 1 and 2.
\end{abstract}

CONCLUSION: Patients with IH present higher IPSS. The role of IPSS as a marker to predict the development of clinical IH still to be determined.

Key words: Hernia, Inguinal. Urinary Tract. Symptoms. Questionnaires.

\section{RESUMO}

OBJETIVO: Verificar a correlação entre a presença de HI e a intensidade dos STUI quantificados através do escore internacional de sintomas prostáticos (IPSS).

MÉTODOS: Foram selecionados prospectivamente 52 pacientes com idade superior a 55 anos; os pacientes foram divididos em 2 grupos. Grupo 1: composto por 32 pacientes portadores de IH, Grupo 2 (grupo controle): composto por 20 pacientes sem evidência clínica de IH. Os parâmetros avaliados foram: sintomas urinários, quantificados através do IPSS; fluxo urinário máximo (Qmax), obtido através da fluxometria livre; resíduo pós miccional (RM) e volume prostático (VP), obtido através do ultrassom transretal.

RESULTADOS: Os grupos 1 e 2 não apresentaram diferença significativa em relação ao Qmax e VP (p>0.05). Foi detectada diferença estatística significativa entre em relação ao VR entre os grupos 1 e $2(p<0.05)$. A presença de HI se correlacionou com o aumento da intensidade dos STUI $(\mathrm{r}=0,38 ; \mathrm{p}<0.05)$. Não foi detectada diferença estatisticamente significativa entre a incidência de pacientes portadores de STUI, leve, moderado ou intenso entre os grupos 1 e 2.

CONCLUSÃO: Pacientes portadores de HI apresentam escore de sintomas (IPSS) mais elevados, entretanto o papel dos sintomas urinários como um dos possíveis fatores causadores do aparecimento de HI ainda não foi determinado.

Descritores: Hernia Inguinal. Sistema Urinário. Sintomas. Questionários. 


\section{Introduction}

Lower urinary tract symptoms (LUTS) are prevalent among aging men. Multiple etiologic factors have been described with the genesis of urinary symptoms, including the effect of aging on the nervous system and bladder, metabolic derangements, changes in fluid regulation, obstruction and autonomic overactivity ${ }^{1}$.

Histologic benign prostatic hyperplasia (BPH) develops also with advancing age. Initial development of microscopic BPH begins as early as $25-30$ years. After the age of 45 the prevalence of BPH increases rapidly, reaching $90 \%$ at the age of 90 . However macroscopic $\mathrm{BPH}$ (prostatic enlargement due to $\mathrm{BPH}$ ) will be detected eventually in half of man with microscopic BPH.

Traditionally, the diagnostic evaluation of patients with LUTS suggestive of bladder outlet obstruction (BOO) includes symptomatic evaluation ${ }^{2}$. Although symptom scoring systems have proved to be a useful tool to quantify clinical symptoms, several studies have shown that none of these scores correlate with BOO and $\mathrm{BPH}$ related complications, furthermore they are not disease specific $^{3-5}$.

The incidence of inguinal hernias $(\mathrm{IH})$ also increases with age. Various factors contribute to the development of $\mathrm{IH}$, including obesity and work-related physical activity and is not uncommon for urologists to face patients presenting LUTS associated to $\mathrm{IH}^{6}$.

The American Urological Association guideline, for BPH, updated in 2006, recommends prostate surgery as first option just for patients presenting refractory retention, gross hematuria, bladder stones, recurrent urinary tract infection and renal insufficiency, all clearly related to $\mathrm{BPH}^{7}$. No recommendations are made in men with concomitant evidence of IH and bothersome LUTS related to $\mathrm{BPH}$.

The aim of this study is to verify the correlation between the presence of IH and the intensity of LUTS, related to BPH, quantified through the IPSS.

\section{Methods}

Between December 2004 and February 2006 we prospectively selected 52 patients over the age of 50 years. The patients were divided in 2 groups according to the presence of $\mathrm{IH}$. Group 1 was composed of 32 patients with IH; Group 2 (control group) was composed of 20 patients with no evidence of IH.

The exclusion criteria was the presence urinary tract infection, urethral stricture, prostate cancer, a past history of abdominal surgery, previous therapy for voiding dysfunction during the last 3 months, or taking medications that could affect the lower urinary tract.

The study was conducted with the approval of the local Research Ethics Committee, and all patients consented to participate.

LUTS were quantified using the 7 question IPSS and the patients were classified as having mild, moderate or severe symptoms according the final IPSS score: IPSS from 0 to 7 - mild symptoms; IPSS from 8 to 19 - moderate symptoms; IPSS $\geq 20$, severe symptom. IH was detected by physical examination by 2 physicians.
Noninvasive parameters of evaluation included uroflowmetry - peak urinary flow rate (Qmax), post-void residual (PVR) and measurement of prostate volume (PV) by transrectal ultrasound. Uroflowmetry was considered a valid test if the voided volume was not less than $150 \mathrm{ml}$.

Statistical analyses were performed using the Statistical Package for the Social Sciences (SPSS ${ }^{\circledR}$ v17.0). The power of associations between the quantitative variables was determined using a Pearson's linear correlation. Two-sided $p$-values $<0.05$ were considered significant. Chi-square test, Student $t$ test were calculated to compare the matched groups in this study.

\section{Results}

The baseline characteristics for Groups 1 and 2 are summarized in Table 1.

Mild, moderate and severe LUTS were present in 4 $(12.5 \%) ; 16(50 \%)$ and $12(\mathrm{n}=37.5 \%)$ patients of Group 1 (patients with $\mathrm{IH})$ and in $6(30 \%) ; 9(45 \%)$ and $5(20 \%)$ patients of Group 2 (patients without IH). The presence of $\mathrm{IH}$ correlated with the presence of higher IPSS $(r=0.38 p<0.05)$ despite the incidence of patients with mild, moderate and severe LUTS did not differ significantly in both groups. Table 2 summarizes the symptom severity distribution between groups 1 and 2 .

TABLE 1 - Patients baseline characteristics.

\begin{tabular}{ccccc}
\hline & $\begin{array}{c}\text { Group 1 } \\
(\mathbf{n = 3 2})\end{array}$ & $\begin{array}{c}\text { Group 2 } \\
(\mathbf{n = 2 0})\end{array}$ & t & p \\
\hline Age: mean / range / & $\begin{array}{c}65.2(55-81) \\
\text { SD }\end{array}$ & $\begin{array}{c}63.4(55-74) \\
\pm 6.1\end{array}$ & 0.91 & 0.37 \\
IPSS: mean / range / & $\begin{array}{c}20.7(8-32) \\
\text { SD }\end{array}$ & $\begin{array}{c}19.2(8-30) \\
\pm 7.6\end{array}$ & 0,71 & 0.48 \\
\hline \multicolumn{4}{c}{} \\
\hline
\end{tabular}

TABLE 2 - Symptom severity distribution for groups 1 and 2 $\left(X^{2}=2,61 ; \mathrm{p}=0,27\right)$.

\begin{tabular}{cccc}
\hline $\begin{array}{c}\text { Symptom } \\
\text { Severity }\end{array}$ & Mild & Moderate & Severe \\
\hline Group 1 & $\mathrm{n}=4(12.5 \%)$ & $\mathrm{n}=16(50 \%)$ & $\mathrm{n}=12(37.5 \%)$ \\
Group 2 & $\mathrm{n}=6(30 \%)$ & $\mathrm{n}=9(45 \%)$ & $\mathrm{n}=5(20 \%)$ \\
\hline
\end{tabular}

The mean values of the noninvasive parameters: uroflowmetry (Qmax), PVR and PV for Groups 1 and 2 are summarized in Table 3. A statistically significant difference was found between the PVR mean values between groups 1 and 2 $(\mathrm{p}<0.05)$.

We did not found any correlation between PV, Qmax and PVR with the LUTS intensity assessed through the IPSS.

TABLE 3 - Mean values of the noninvasive parameters in groups 1 and 2 .

\begin{tabular}{lcccc}
\hline & $\begin{array}{c}\text { Group 1 } \\
(\mathbf{n}=32) \\
\text { Mean } \pm \text { SD }\end{array}$ & $\begin{array}{c}\text { Group 2 } \\
(\mathbf{n = 2 0}) \\
\text { Mean } \pm \text { SD }\end{array}$ & t & p \\
& $11.4 \pm 2.9$ & $12.6 \pm 3.1$ & -1.41 & 0.16 \\
Qmax (ml/sec) & $55.6 \pm 29.3$ & $37.8 \pm 22.3$ & 2.48 & 0.02 \\
PVR (ml) & $48.9 \pm 11.4$ & $50.7 \pm 9.4$ & 0.59 & 0.56 \\
PV (ml): mean / SD & & & & \\
\hline
\end{tabular}




\section{Discussion}

Symptoms from lower urinary tract are non specific and difficult to link to a specific process. However, LUTS represent the most common clinical manifestation of BPH. Abrams reported that the fear for cancer, the urinary symptoms which many patients fear may get worse and necessitate treatment later, and the bothersome of urinary symptoms affecting quality of life, are the most frequent reasons that results in medical consultation ${ }^{8}$.

Recent reports have uncovered a remarkable association of BPH, erectile dysfunction and chronic pelvic pain syndrome 9 . These facts raised an important question: Should BPH be considered the primary mechanism of lower urinary tract dysfunction or just one component of the aging process affecting men?

In the early 19th century, the cause of herniation was speculated upon and was considered to be due to "a mechanical disparity between the visceral pressure and the resistance of the abdominal musculature" and also due to "the strength of an abdominal wall which was considered to be diminished by deficiency, debility or aging" A common set of factors that were often evoked as causative in the genesis of a hernia were: cough, obesity, constipation, benign prostatic hypertrophy, pregnancy, ascites, and heavy lifting.

Today we have progressed from the simple concept of increased intra-abdominal pressure overwhelming a weak abdominal wall to the complex malady that calls upon several basic sciences to explain the multitudinous facets, though one final common pathway, of its pathophysiology. The target organ of all the known injurious stimuli is the collagen matrix, which is also related to the aging process in bladder and others organs ${ }^{10}$.

To our knowledge, our study is the first to evaluate for the correlation between the LUTS quantified through the IPSS and presence of $\mathrm{IH}$.

Many authors reported the lack of correlation or a poor correlation between prostate size estimate by Trus and Luts ${ }^{11,12}$. Different methods can be applied to estimate prostate volume. Digital rectum examination (DRE) is the most inexpensive and non invasive method but its accuracy with prostate size is poor ${ }^{13}$. In a study comparing the accuracy of DRE and TRUS to estimate prostate volume, Meyhoff et al. ${ }^{14}$ confirmed the superiority of TRUS compared to DRE to assess prostate size. We did not find a positive correlation between prostate volume and the presence LUTS.

We did not found a statistically significance difference between the number of men with mild, moderate and severe LUTS symptoms between groups 1 and 2, but the presence of $\mathrm{IH}$ correlated with a higher IPSS.

A possible explanation for this association remains on the fact that patients with obstructive voiding dysfunction may need to strain to void, this effort over time may have a direct impact on the abdominal wall contributing to the development of $\mathrm{IH}$, another possibility remains on the fact that $\mathrm{IH}$ and $\mathrm{BPH}$ are part of the aging process which incorporates other functional and anatomic disorders, if all these changes have a cause effect relation or are independent factors just related to the aging process, are still to be defined.
The statistically significance difference found between the mean PVR values between groups 1 and 2 cannot be extrapolated to diagnose $\mathrm{BOO}$ or associate to $\mathrm{BPH}$ related complications. Uroflowmetry and PVR are recognized as noninvasive screening tests that can show if voiding is normal or abnormal, their results cannot be extrapolated. In fact the maximum flow rate is a function of detrusor contraction and de degree of $\mathrm{BOO}$ and is impossible to distinguish safely patients with BOO from those with detrusor underactivity ${ }^{5,15,16}$. There are limited data regarding the normal residual urine volume in asymptomatic patients and until now no consensus has been reached to the relationship between residual urine, $\mathrm{BOO}$ and detrusor underactivity. In addition, the residual urine volume can vary over time especially in elderly patients ${ }^{17}$.

The incidence of IH in men undergoing prostatic surgery is $15-25 \%$, in addition $11-30 \%$ of patients who were submitted to surgical IH repair and presented LUTS precipitate postoperative retention requiring urological intervention ${ }^{18-20}$. Urologists should be aware of this association and advise their patients of the possible consequences.

The main shortcoming of the present study is the presence of small number of patients, which must be expanded in the future to confirm our findings.

Further studies are necessary to investigate if men with $\mathrm{IH}$ and complaining of urinary symptoms related to BPH have a higher risk to present urodynamic $\mathrm{BOO}$ and are more suitable to $\mathrm{BPH}$ related complications or if the presence of LUTS predispose the development of IH.

\section{Conclusion}

Patients with IH present higher IPSS when compared with patients without IH. Urologists should be aware of this association. The role of IPSS as a marker to predict the development of clinical IH still to be determined.

\section{References}

1. Madersbacher S, Klingler HC, Schatzl G, Stulnig T, Schmidbauer CP, Marberger M. Age related urodynamic changes in patients with benign prostatic hyperplasia. J Urol. 1996;156:1662-7.

2. Barry MJ. Evaluation of symptoms and quality of life in men with benign prostatic hyperplasia. Urology. 2001;58:25-32.

3. Yalla SV, Sullivan MP, Lecamwasam HS, DuBeau CE, Vickers MA, Carvalho EG Correlation of the American Urological Association symptom index with obstructive and nonobstructiveprostatism. J Urol. $1995 ; 153 ; 674-9$.

4. Chancellor MB, Rivas DA. American Urological Association symptom index for women with voiding symptoms: lack of index specificity for benign prostatic hyperplasia. J Urol. 1993;150:1706-11.

5. Nitti VW, Kim Y, Combs AJ. Correlation of the AUA symptom index with urodynamics in patients with suspected benign prostatic hyperplasia. Neurourol Urodyn. 1994;13:521-7.

6. Tundidor-Bermudez AM. Hernia inguinal y prostatismo. Arch Esp Urol. 1994;47:19-21.

7. Kaplan SA. Update on the American Urological Association guidelines for the treatment of benign prostatic hyperplasia. Rev Urol. 2006;8:S10-17. 8. Abrams P. Evaluating lower urinary tract symptoms suggestive of benign prostatic obstruction. Scand J Urol Nephrol. 1999;203:1-7. 
9. Costabile RA, Steers WD. How can we best characterize the relationship between erectile dysfunction and benign prostatic hyperplasia? J Sex Med. 2006;3:676-81.

10. Bendavid R. The unified theory of hernia formation. Hernia. 2004;8:171-6.

11. Ozayar A, Zumrutbas AE, Yaman O. The relationship between lower urinary tract symptoms (LUTS), diagnostic indicators of benign prostatic hyperplasia (BPH), and erectile dysfunction in patients with moderate to severely symptomatic BPH. Int Urol Nephrol. 2008;40:933-39.

12. Rosier PF, La Rosette JJ. Is there a correlation between prostate size and bladder-outlet obstruction? World J Urol. 1995;13:9-14.

13. Loeb S, Han M, Roehl K A, Antenor JAV, Catalona WJ. Accuracy of prostate weight estimation by digital rectal examination versus transrectal ultrasonography. J Urol. 2005;173:63-7.

14. Meyhoff HH, Ingemann L, Nordling J, Hald T. Accuracy in preoperative estimation of prostatic size. A comparative evaluation of rectal palpation, intravenous pyelography, urethral closure pressure profile recording and cystourethroscopy. Scand J Urol Nephrol. 1981;15:45-50.
15. Girman CJ, Jacobsen SJ, Guess HA, Oesterling JE, Chute CG, Panser LA, Lieber MM. Natural history of prostatism: relationship among symptoms, prostate volume and peak urinary flow rate. J Urol. 1995; 153:1510-5.

16. Netto Júnnior NR, D’Ancona CA, Lima ML. Correlation between the International Prostatic Symptom Score and a pressure-flow study in the evaluation of symptomatic benign prostatic hyperplasia. J Urol. 1996;155:200-21.

17. Hansen F, Olsen L, Atan A, Jakobsen H, Nordeling J. Pressure-flow studies: an evaluation of within-testing reproducibility-validity of the measured parameters. Neurourol Urodyn. 1997;16:521-32.

18. Jasper WS Sr. Combined open prostatectomy and herniorrhaphy. J Urol. 1974;111:370-3.

19. McDonald DF, Huggins C. Simultaneous prostatectomy and inguinal herniorrhaphy. Surg Gynecol Obstet. 1949;89:621-4.

20. Devarajan R, Jaganathan RS, Harriss DR, Chua CB, Bishop MC. Combined transurethral prostatectomy and inguinal hernia repair: a retrospective audit and literature review. BJU Int. 1999;84:637-9.

\section{Correspondence:}

Rodolfo Borges dos Reis

Rua João Gomes Rocha, 835/162

14020-550 Ribeirão Preto - SP Brasil

Tel./Fax: (55 16) 3602-2593

rodolforeis@fmrp.usp.br

rodolfosbusp@uol.com.br

Conflict of interest: none

Financial source: none

${ }^{1}$ Research performed at Division of Urology, Department of Surgery and Anatomy, Faculty of Medicine of Ribeirao Preto, University of Sao Paulo (FMRP-USP), Ribeirao Preto-SP, Brazil.

Presented at the XII National Congress on Experimental Surgery of the Brazilian Society for Development of Research in Surgery-SOBRADPEC, 2011 October 26-29 Ribeirao Preto-SP, Brazil. 